\title{
Review
}

Wayne R. Cohen* and Emanuel A. Friedman

\section{Clinical evaluation of labor: an evidence- and experience-based approach}

https://doi.org/10.1515/jpm-2020-0256

Received June 6, 2020; accepted September 17, 2020;

published online October 19, 2020

Abstract: During labor mother and fetus are evaluated at intervals to assess their well-being and determine how the labor is progressing. These assessments require skillful physical diagnosis and the ability to translate the acquired information into meaningful prognostic decision-making. We describe a coordinated approach to the assessment of labor. Graphing of serial measurements of cervical dilatation and fetal station creates "labor curves," which provide diagnostic and prognostic information. Based on these curves we recognize nine discrete labor abnormalities. Many may be related to insufficient or disordered contractile mechanisms. Several factors are strongly associated with development of labor disorders, including cephalopelvic disproportion, excess analgesia, fetal malpositions, intrauterine infection, and maternal obesity. Clinical cephalopelvimetry involves assessing pelvic traits and predicting their effects on labor. These observations must be integrated with information derived from the labor curves. Exogenous oxytocin is widely used. It has a high therapeutic index, but is easily misused. Oxytocin treatment should be restricted to situations in which its potential benefits clearly outweigh its risks. This requires there be a documented labor dysfunction or a legitimate medical reason to shorten the labor. Normal labor and delivery pose little risk to a healthy fetus; but dysfunctional labors, especially if stimulated excessively by oxytocin or terminated by complex operative vaginal delivery, have the potential for considerable harm. Conscientiously implemented, the approach to the evaluation of labor outlined in this review will result in a reasonable cesarean rate and minimize risks that may accrue from the labor and delivery process.

*Corresponding author: Wayne R. Cohen, MD, Clinical Professor of Obstetrics and Gynecology, University of Arizona, 4841 North Valley View Rd, Tucson, AZ 85718, USA, Phone: 520505 4213, Fax 520505 4213, Mobile: 646270 5518, E-mail: cohenw@email.arizona.edu Emanuel A. Friedman, Department of Obstetrics, Gynecology and Reproductive Biology, Harvard Medical School, Boston, MA, USA
Keywords: birth; cephalopelvimetry; labor; labor curves; pelvimetry; second stage labor.

\section{Introduction}

Human labor and birth, extraordinary events refined by evolution to have ably sustained our species over 200 millennia, are delicately programmed and awe-inspiring. Their physiology and mechanics are so complex it is remarkable that in most cases they occur smoothly and without maternal or fetal adversity. Although many advances have been made in the last half-century to improve obstetric care, there is still far to go to enhance our understanding of the process and to optimize outcomes.

Western childbirth practices have changed substantially over the last century. Birthing has become primarily hospital-based; safe anesthetic techniques are in widespread use; synthetic oxytocin and electronic fetal heart rate monitoring are employed in most labors; and rates of cesarean delivery and labor induction have risen. The virtues of these shifts in practice patterns are controversial, but they serve to emphasize the importance of understanding the ways in which changing patient expectations and practice models affect our interpretation of labor progress.

In concert with most specialties, obstetric practice has become increasingly dependent on biotechnologic innovations. The assessment of labor progress, however, remains primarily an exercise in skillful physical diagnosis coupled with the ability to translate the acquired information into meaningful prognostic decision making [1]. This review, which focuses on labors of singleton term pregnancies with cephalic presentations, addresses practical aspects of the assessment of labor that should be mastered by all clinicians who assist women during birth.

\section{Serial examination}

During labor, mother and fetus are evaluated at intervals to assess their well-being and to determine how the labor is progressing. It is likely that a major benefit of prenatal care is that it fosters bonds of communication and trust between 
clinician and patient that serve both well during labor, particularly if complications arise that require difficult decisions be made. The advent of laborists in many hospitals has eliminated this advantage, as has the trend to very large group practices. The relative advantages and compromises associated with these new practice patterns have yet to be ascertained.

The frequency of examinations during labor is dictated by the extant circumstances. However, it is important to note that supportive companionship and observation of the parturient should be continuous. As such, it can be expected to yield psychological and perhaps medical dividends [2, 3].

At each evaluation maternal physical and emotional condition and needs are assessed. An appraisal of how well the fetus is tolerating labor is made and the frequency and intensity of uterine contractions is determined. The birth canal is examined systematically, yielding considerable pertinent information (Table 1). Cervical dilatation and fetal station are noted. The aggregate of observations is considered in relation to antecedent examinations. A determination is made regarding the probability that, if labor continues along its current trajectory, it will result in a safe vaginal birth. Such predictions are based primarily on objective data, but entail inferences about many interacting variables that influence whether a labor will advance and resolve normally.

\section{The labor curves}

Prior to the 1960s, decisions about the need to intervene in a labor were based primarily on the experience-based judgments of obstetricians and midwives. These often involved notions of how long labor should persist before

Table 1: Evaluation of the fetus and birth canal (cephalopelvimetry).

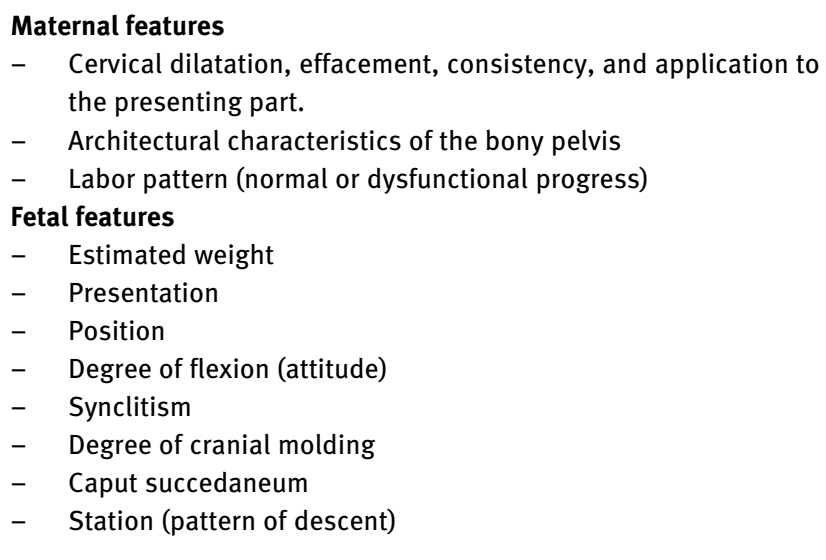

fetal or maternal damage might ensue, notions that arose from what we now know was a simplistic and inaccurate knowledge base.

Labor progresses over time, and many attempts to characterize and to quantitate this function in a clinically meaningful way have been made [4]. The most enduring, derived from the work of Friedman, describe how cervical dilatation and fetal station change over time in labor $[5,6]$. These graphic patterns (often called labor curves) have served as the basis for all subsequent approaches to characterize labor progress. To visualize the progressive change, the attendant is best served by plotting them on simple square-ruled graph paper (Figure 1) with time elapsed during labor on the horizontal axis. Although other observations need to be considered, the pattern of change in dilatation and station against time is the best indicator of whether labor progress is normal. These graphic patterns should be plotted in real time in every labor record as a visual tool to facilitate recognition of abnormal progress promptly and accurately.

The onset of labor can only be estimated. It may generally be assumed to have begun when uncomfortable uterine contractions regularize. Labor begins with a latent phase, in which progress in dilatation and station is slow or absent. Uterine contractions generally begin as infrequent and mild in intensity. Mechanistically, the latent phase is a time of preparation of the cervix for the more rapid dilatation and descent to come.

Through enzymatic hydrolysis of collagen, ground substance modifications, and smooth muscle relaxation, the cervix and lower uterine segment mature, i.e., they soften and may begin to efface and dilate slowly. The duration of the latent phase is inversely proportional to the amount of cervical maturation that has occurred prior to the initiation of labor [6]. That is, the more prelabor dilatation, the shorter the latent phase will be. When descent of

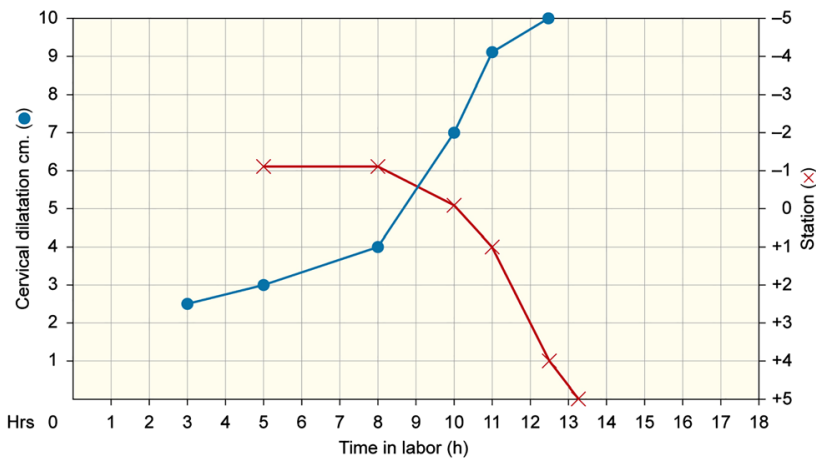

Figure 1: Characteristic patterns of normal cervical dilatation and fetal descent depicted graphically against elapsed time. 
the presenting part occurs in the latent phase, it is generally an accommodation to the development of a more spacious and distensible lower uterine segment.

The energy of latent phase contractions is directed primarily at the cervix and lower uterus. Once these tissues have become sufficiently pliant, uterine contractions exert a centrifugal force that dilates the cervix. Meanwhile, gap junctions form between myometrial cells, affording lowresistance pathways for coordinated electrophysiologic communication throughout the uterus. When proper conditions are achieved, the latent phase gives way to the active phase of labor.

During active phase, dilatation becomes more rapid and, after a brief period of acceleration in rate, the pattern forms a straight line. As the cervix nears complete dilatation, its progress appears to slow. This deceleration phase is an artifact observed because the cervix is no longer opening in the mother's transverse plane, in which it is measured. Rather, it is being pulled cephalad, i.e., parallel to the mother's long axis, along the outer boundary of the fetal head toward full dilatation, at which time it reaches the widest diameter of the head.

Fetal descent follows a pattern similar to that of dilatation (Figure 1). It has a latent phase with slow or absent progress, paralleling the latent phase of the dilatation process, but continuing well into the active phase of dilatation. Following this, descent begins to accelerate and usually becomes progressively faster during the time when dilatation has reached its maximum slope. By the time the deceleration phase of dilatation begins, descent has generally reached its maximum slope, and it progresses at an even rate until it slows just prior to delivery when the fetal head encounters resistance from the pelvic floor and the perineum.

Once the graphic pattern of labor described by Friedman was verified in large samples, statistical limits of normal and characteristic deviations from normal were identified $[1,6]$. As a consequence, we are able to recognize nine discrete labor abnormalities (Table 2, Figure 2). Most of these are various manifestations of slower than normal or arrested progress in dilatation or descent. Two represent excessively rapid rates of progress. The associated risk of short-and long-term neurologic handicap and of obstetric complications such as shoulder dystocia and the need for cesarean delivery have been reported, as have the influence of factors such as maternal parity, age, obesity, anesthetic and analgesic drugs and oxytocin on labor progress [1, 6-11].

The specific causes of the various forms of dysfunctional labor are not completely understood. Many may be
Table 2: Dysfunctional labor patterns.
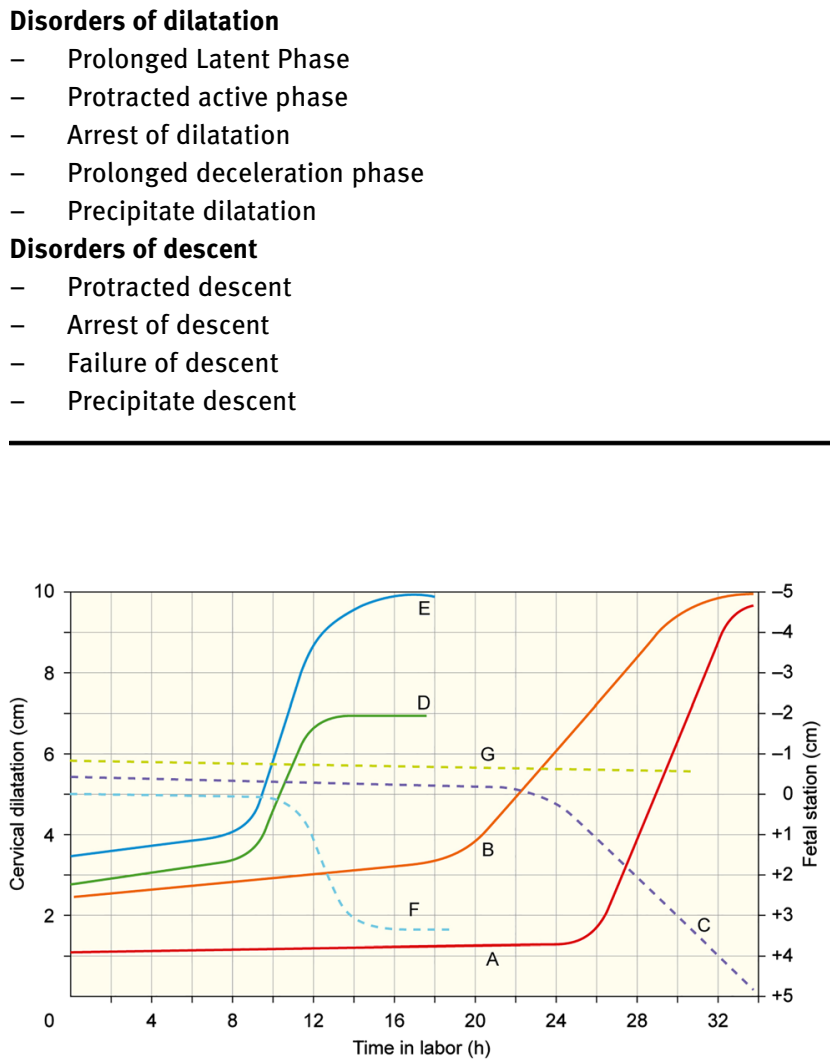

Figure 2: Labor disorders that can be identified on the basis of deviations from the expected normal duration, slopes and patterns of the dilatation and descent curves are illustrated graphically. (A) Prolonged latent phase; (B) Protracted dilatation; (C) Protracted descent; (D) Arrest of dilatation; (E) Prolonged deceleration phase; (F) Arrest of descent; (G) Failure of descent. By permission from Cohen WR and Friedman EA in Kurjak A, Chervenak FA (eds) Textbook of Perinatal Medicine, $2^{\text {nd }}$ edition. Informa UK, London, 2006:p1824.

related to insufficient or disordered contractility, but changes in contractility could be either the cause or the consequence of dysfunctional labor. For example, infection, hypoxia or cephalopelvic disproportion (CPD) might trigger mechanisms we do not understand that signal the uterus to reduce contractility. This in turn may protect the fetus from oxygen deprivation or excess cranial compression. We do know that several factors are strongly associated with the development of protraction and arrest disorders, including CPD, excess analgesia, fetal malpositions, intrauterine infection, and maternal obesity (Table 3). When more than one disorder occurs in the same labor, their effects are additive, or at least synergistic. Management and significance of various labor progress disorders are summarized in Table 4 and Figures 3 and 4. 
Table 3: Clinical associations of protraction and arrest disorders.

\begin{tabular}{ll}
\hline - & Cephalopelvic disproportion \\
- & Malposition \\
- & Malpresentation \\
- & Excess maternal analgesia \\
- & Maternal obesity \\
- & Uterine infection \\
- & Advanced maternal age \\
- & Previous cesarean delivery \\
- Insufficient uterine contractility
\end{tabular}

For example, a labor with an arrest of dilatation that follows a protracted active phase is more likely to require cesarean delivery than one in which the arrest occurred during a previously normal active phase. Similarly, when a long second stage occurs in the wake of a prolonged deceleration phase of labor cesarean delivery or, if vaginal delivery occurs, shoulder dystocia and brachial plexus injury are more likely than if either labor dysfunction occurred alone [6, 10, 11].
The descriptions of normal cervical dilatation and fetal descent described by Friedman have been confirmed, replicated, and found effective for clinical practice by many investigators around the world [12-18]. There have been small variations on the original theme, but the basic structure of the labor curves, and specifically a linear active phase progression of about $1 \mathrm{~cm} / \mathrm{h}$ has been confirmed by almost all investigators over the last 60 years.

The breadth of this confirmatory evidence notwithstanding, an alternative model for assessing the normality of labor progress has recently been promulgated [19, 20], and has been accepted in guidelines of the Society for Maternal-Fetal Medicine and the American College of Obstetricians and Gynecologists [21]. There are many reasons why this new model is insufficient and should not supplant traditional clinical paradigms [22-25]. Most important, it has not been shown to be superior to, or even the equivalent of the traditional approach in terms of safety for mother and fetus or its clinical ability to detect abnormal labor progress.

Table 4: Dysfunctional labor patterns: definition and significance.

\begin{tabular}{|c|c|c|c|c|}
\hline $\begin{array}{l}\text { Labor pattern } \\
\text { abnormality }\end{array}$ & Definition (nulliparas) & Definition (multiparas) & Recommended management & Significance \\
\hline $\begin{array}{l}\text { Prolonged latent } \\
\text { phase }\end{array}$ & $\begin{array}{l}\text { Latent phase duration ex- } \\
\text { ceeds } 20 \mathrm{~h}\end{array}$ & $\begin{array}{l}\text { Latent phase duration ex- } \\
\text { ceeds } 14 \mathrm{~h}\end{array}$ & Oxytocin or sedation. & Increased risk of cesarean. \\
\hline $\begin{array}{l}\text { Protracted active } \\
\text { phase }\end{array}$ & $\begin{array}{l}\text { Active phase rate of prog- } \\
\text { ress is }<1.2 \mathrm{~cm} / \mathrm{h}\end{array}$ & $\begin{array}{l}\text { Active phase rate of prog- } \\
\text { ress is }<1.5 \mathrm{~cm} / \mathrm{h}\end{array}$ & $\begin{array}{l}\text { Observation, support, unless } \\
\text { caused by inhibitory factors; } \\
\text { then, oxytocin. }\end{array}$ & $\begin{array}{l}\text { Approx } 25 \% \text { require cesarean } \\
\text { for CPD. }\end{array}$ \\
\hline $\begin{array}{l}\text { Arrest of } \\
\text { dilatation }\end{array}$ & $\begin{array}{l}\text { No active phase progress } \\
\text { for } 2 \mathrm{~h} \text { or longer }\end{array}$ & $\begin{array}{l}\text { No active phase progress } \\
\text { for } 2 \mathrm{~h} \text { or longer }\end{array}$ & $\begin{array}{l}\text { Oxytocin if CPD unlikely. } \\
\text { Cesarean if CPD probable. }\end{array}$ & $\begin{array}{l}\text { Approx } 40 \% \text { require cesarean } \\
\text { for CPD. } \\
\text { Associated with excessive } \\
\text { analgesia, infection, obesity, } \\
\text { malposition. }\end{array}$ \\
\hline $\begin{array}{l}\text { Prolonged } \\
\text { deceleration } \\
\text { phase }\end{array}$ & $\begin{array}{l}\text { Deceleration phase ex- } \\
\text { ceeds } 2 \mathrm{~h}\end{array}$ & $\begin{array}{l}\text { Deceleration phase ex- } \\
\text { ceeds } 1 \mathrm{~h}\end{array}$ & $\begin{array}{l}\text { Oxytocin if CPD unlikely. } \\
\text { Cesarean if CPD probable. } \\
\text { Cesarean if other risk factors } \\
\text { for shoulder dystocia exist. }\end{array}$ & $\begin{array}{l}\text { Associated with CPD, shoulder } \\
\text { dystocia, malpositions, exces- } \\
\text { sive sedation or analgesia. }\end{array}$ \\
\hline $\begin{array}{l}\text { Protracted } \\
\text { descent }\end{array}$ & $\begin{array}{l}\text { Active descent rate of } \\
\text { progress is }<1 \mathrm{~cm} / \mathrm{h}\end{array}$ & Active descent $<2 \mathrm{~cm} / \mathrm{h}$ & $\begin{array}{l}\text { Observation, support, unless } \\
\text { caused by inhibitory factors. } \\
\text { Cesarean if CPD probable. }\end{array}$ & Associated with CPD. \\
\hline Arrest of descent & $\begin{array}{l}\text { Active descent ceases for } \\
1 \mathrm{~h} \text { or more }\end{array}$ & $\begin{array}{l}\text { Active descent ceases for } \\
1 \mathrm{~h}\end{array}$ & $\begin{array}{l}\text { Oxytocin, if CPD unlikely. } \\
\text { Cesarean if CPD probable. }\end{array}$ & Strong association with CPD. \\
\hline $\begin{array}{l}\text { Failure of } \\
\text { descent }\end{array}$ & $\begin{array}{l}\text { No descent from onset of } \\
\text { active phase to decelera- } \\
\text { tion phase or full dilatation }\end{array}$ & $\begin{array}{l}\text { No descent from onset of } \\
\text { active phase to decelera- } \\
\text { tion phase or full dilatation }\end{array}$ & $\begin{array}{l}\text { Oxytocin if CPD unlikely. } \\
\text { Cesarean if CPD probable. }\end{array}$ & $\begin{array}{l}\text { Strong association with CPD, } \\
\text { especially if occurs with } \\
\text { oxytocin. }\end{array}$ \\
\hline $\begin{array}{l}\text { Precipitate } \\
\text { dilatation } \\
\text { Precipitate } \\
\text { descent }\end{array}$ & $\begin{array}{l}\text { Active phase dilatation is } \\
>5 \mathrm{~cm} / \mathrm{h} \\
\text { Active phase dilatation is } \\
>5 \mathrm{~cm} / \mathrm{h}\end{array}$ & $\begin{array}{l}\text { Active phase dilatation is } \\
>10 \mathrm{~cm} / \mathrm{h} \\
\text { Active phase descent is } \\
>10 \mathrm{~cm} / \mathrm{h}\end{array}$ & $\begin{array}{l}\text { Usually too late to treat when } \\
\text { diagnosed. } \\
\text { If time allows, uterine contrac- } \\
\text { tions may be inhibited with } \\
\text { tocolytic agent. }\end{array}$ & $\begin{array}{l}\text { Predisposes to uncontrolled } \\
\text { delivery, birth canal injury, } \\
\text { fetal damage, shoulder } \\
\text { dystocia. }\end{array}$ \\
\hline
\end{tabular}




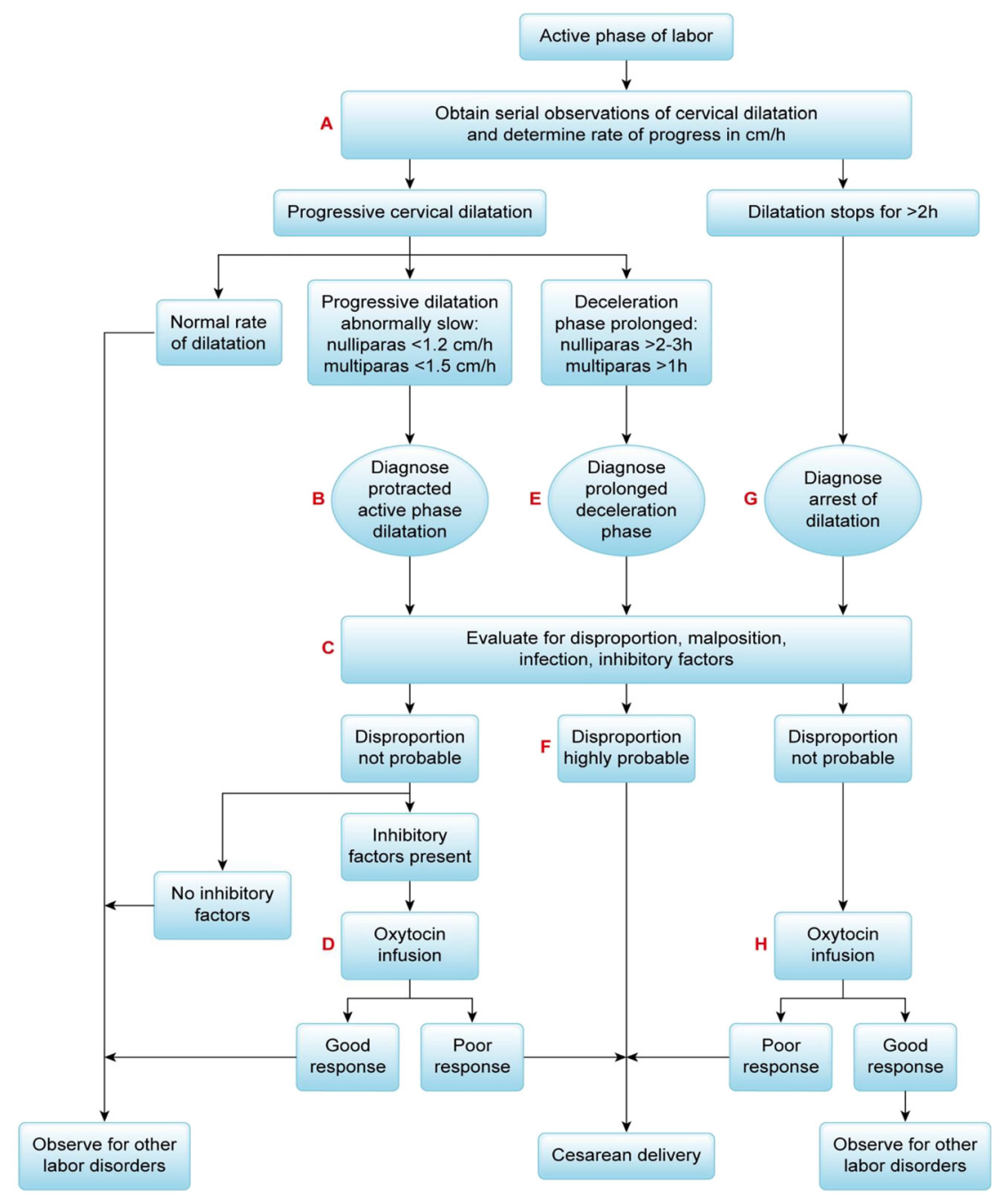

Figure 3: Management of the active phase of labor.

(A) Recognize onset of the active phase by the upswing of the cervical dilatation curve. If the rate of dilatation is normal, continue close observation, but no intervention is necessary. (B) If the rate of active phase dilatation in a nullipara is $<1.2 \mathrm{~cm} / \mathrm{h}$ or in a multipara $<1.5 \mathrm{~cm} / \mathrm{h}$ diagnose a protracted active phase. (C) If there is a protracted active phase search for inhibitory factors (e.g., excess analgesia/anesthesia, marked obesity, excess analgesia, etc.) Do thorough cephalopelvimetry. If disproportion is highly probable, proceed to cesarean delivery. (D) If disproportion seems unlikely and inhibitory factors are present, stimulate contractions with oxytocin. A good response (more rapid dilatation) bodes well for vaginal delivery; a poor response suggests cesarean delivery is more appropriate. (E) Prolonged deceleration phase is often associated with cephalopelvic disproportion as well as occiput posterior position and shoulder dystocia. (F) If the probability of cephalopelvic disproportion is high in the presence of a protraction or arrest disorder, it is prudent to undertake cesarean delivery as the safest option. (G) Arrest of dilatation is diagnosed when active phase progress has ceased for $2 \mathrm{~h}$. If there is no concern about disproportion, use oxytocin. If disproportion is strongly suspected, proceed to cesarean delivery. $(\mathrm{H})$ When oxytocin is used for an arrest disorder, most patients will respond in 3-4 h. If there is no response, or if the post-arrest slope is lower than the prearrest slope, cesarean delivery is warranted. By permission from Cohen WR, Friedman EA. Labor and Delivery Care. A Practical Guide. John Wiley \& Sons, Oxford, 2011, pp. 90-91.

In addition, Friedman's data were derived from direct clinical observation and confirmed by mechanical and ultrasonographic cervimetry; recent studies used an errorprone retrospective curve-fitting approach to analyze an existing database. The results were likely biased by unadjusted confounders and inappropriate case selection
[22]. The new guidelines advocate much longer labors in both first and second stage than have generally been recommended, but offer no evidence that such long labors are consistent with maternal and fetal well-being.

The principal goal of the new guidelines is to provide clinicians a means to reduce their reliance on primary 


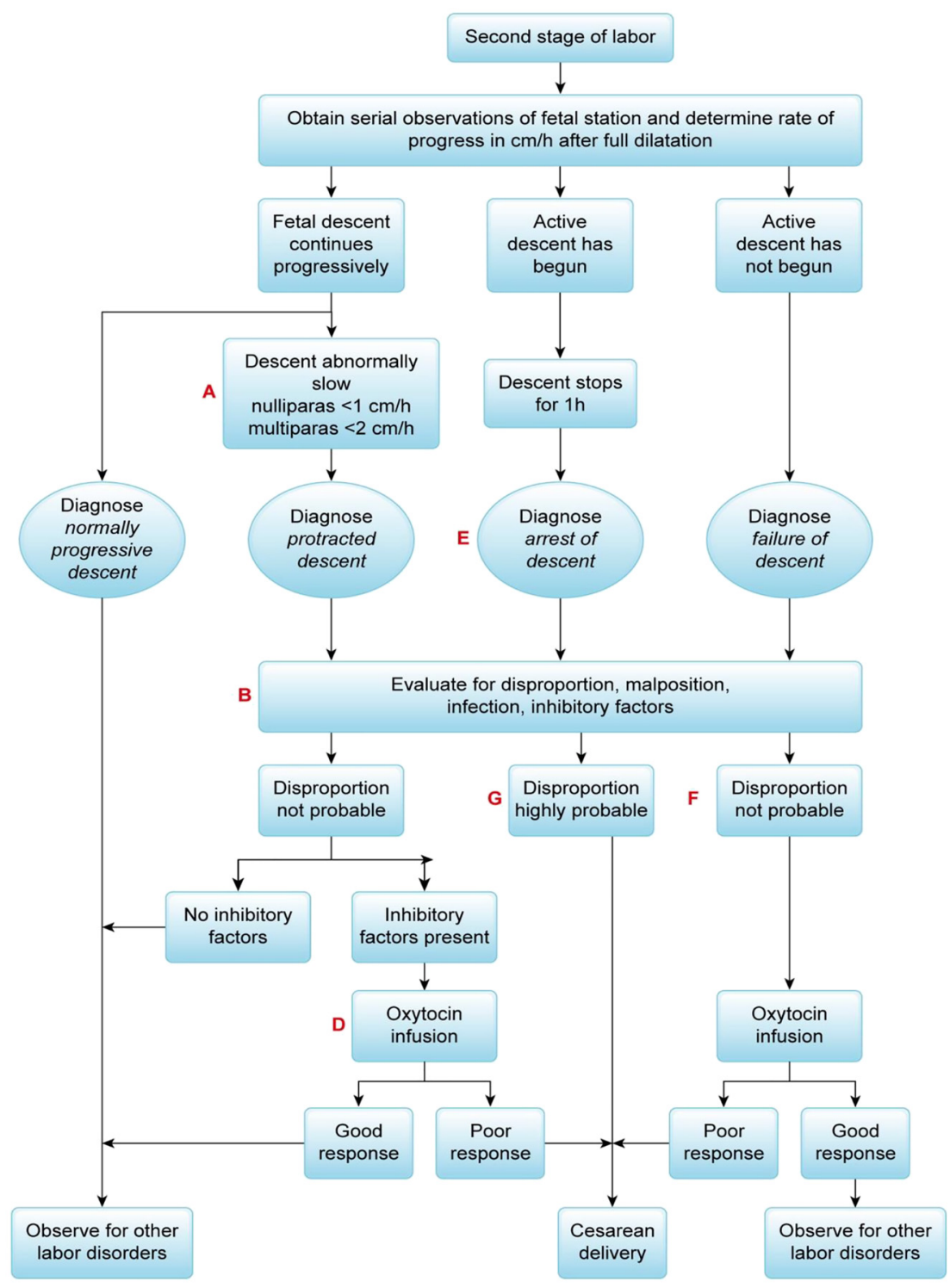

Figure 4: Management of the second stage of labor.

(A) The rate of fetal descent is determined by serial measurements of fetal station. Once descent begins in late first stage or in second stage, it should be at least one station $(\mathrm{cm}) / \mathrm{h}$ in nulliparas or $2 \mathrm{~cm} / \mathrm{h}$ in multiparas. If less, diagnose protracted descent. (B) If cephalopelvic disproportion is highly probable based on cephalopelvimetry, cesarean delivery is justified. (C) If inhibitory factors exist, give oxytocin. If not, oxytocin is unlikely to increase the rate of descent. (D) Allow inhibitory conditions (e.g., excess analgesia, high neuraxial block) to abate. Oxytocin may sometimes speed descent. (E) If, after active linear descent has begun, it ceases for $1 \mathrm{~h}$, diagnose arrest of descent. Search for signs of disproportion using cephalopelvimetry. If there are signs of disproportion, proceed to cesarean delivery; if not, consider oxytocin infusion. (F) If active descent fails to begin when it ordinarily does by the time the labor enters the second stage, diagnose failure of descent. Do thorough cephalopelvimetry. (G) If no evidence of disproportion exists, consider oxytocin; if there is evidence of disproportion, proceed to cesarean delivery. By permission, from Cohen WR, Friedman EA. Labor and Delivery Care. A Practical Guide. John Wiley \& Sons, Oxford, 2011, pp. 92-93. cesarean delivery, because cesarean rates have increased substantially over recent decades. While restraining the rising cesarean rate may be desirable, the guidelines propose a means to do so without regard for its effect on fetal and maternal outcome.

\section{Cephalopelvimetry}

The osseous architecture of the pelvis and its soft tissue structures influence the mechanism of labor, i.e., the manner in which the fetus negotiates the birth canal during its descent [26-28]. The classic pelvic bony phenotypes (gynecoid, anthropoid, android, and platypelloid) are familiar to most clinicians [29]. The individual features of a given pelvis, however, are often derived from more than one archetype. A capable and experienced clinician will be able to recognize these traits and make inferences about their effect on progress in labor (Table 5). For example, a pelvis with overall anthropoid characteristics may, nevertheless, have an anteriorly angled flattened sacrum (generally considered android features), thus resisting fetal descent in an occiput posterior position.

Clinical cephalopelvimetry requires assessment of individual pelvic traits and prediction of their specific and aggregate effects on labor progress [1]. These conclusions need to be integrated with information derived from the labor curves. Thus, when a pelvis has a narrow subpubic arch, a long steeply inclined symphysis pubis, and a flattened sacral curve, characteristic of an android pelvic type, and the labor manifests a prolonged deceleration phase, the likelihood of shoulder dystocia is high. 
Table 5: Interpretation of intrapartum cephalopelvimetric findings.

\begin{tabular}{|c|c|}
\hline Finding & Significance \\
\hline Unengaged head & $\begin{array}{l}\text { In nullipara, risk factor for CPD, espe- } \\
\text { cially at pelvic inlet, or fetal malposition. }\end{array}$ \\
\hline $\begin{array}{l}\text { Large estimated fetal } \\
\text { weight }\end{array}$ & $\begin{array}{l}\text { Risk factor for CPD, dysfunctional labor } \\
\text { pattern, and shoulder dystocia. }\end{array}$ \\
\hline $\begin{array}{l}\text { Fetal malposition, } \\
\text { malpresentation }\end{array}$ & $\begin{array}{l}\text { May preclude further safe labor, or be } \\
\text { risk factor for CPD, or signal non- } \\
\text { gynecoid pelvic architecture. }\end{array}$ \\
\hline $\begin{array}{l}\text { Long, steeply inclined } \\
\text { symphysis pubis }\end{array}$ & $\begin{array}{l}\text { Suspect android pelvis, and possible } \\
\text { shoulder dystocia. }\end{array}$ \\
\hline $\begin{array}{l}\text { Sacrospinous ligaments } \\
\text { short, thick }\end{array}$ & $\begin{array}{l}\text { Possible narrow midpelvis posteriorly. } \\
\text { Sacral curve may be shallow; posterior } \\
\text { space may be insufficient. }\end{array}$ \\
\hline $\begin{array}{l}\text { Sacrospinous ligaments } \\
\text { long }\end{array}$ & $\begin{array}{l}\text { Suspect anthropoid pelvis with posteri- } \\
\text { orly recessed sacrum; or suspect flat } \\
\text { pelvis with widely separated sidewalls. }\end{array}$ \\
\hline Diagonal conjugate short & $\begin{array}{l}\text { Suspect flat or generally contracted } \\
\text { pelvis; consider inlet disproportion. }\end{array}$ \\
\hline $\begin{array}{l}\text { AP dimension of outlet } \\
\text { short }\end{array}$ & $\begin{array}{l}\text { May deliver occiput transverse; anterior } \\
\text { shoulder may not stem beneath sym- } \\
\text { physis pubis causing shoulder dystocia. }\end{array}$ \\
\hline Narrow subpubic arch & $\begin{array}{l}\text { Pelvis may have android or anthropoid } \\
\text { features. Higher risk for perineal tears } \\
\text { and difficult shoulder delivery. }\end{array}$ \\
\hline Sidewalls convergent & $\begin{array}{l}\text { Funnel pelvis. Possible android or an- } \\
\text { thropoid characteristics. High risk for } \\
\text { CPD and shoulder dystocia }\end{array}$ \\
\hline Ischial spines prominent & $\begin{array}{l}\text { May inhibit anterior or posterior rotation } \\
\text { of head }\end{array}$ \\
\hline $\begin{array}{l}\text { Sacral curvature absent or } \\
\text { shallow }\end{array}$ & $\begin{array}{l}\text { May prevent posterior rotation of } \\
\text { occiput; may impair descent of posterior } \\
\text { shoulder resulting in shoulder dystocia. }\end{array}$ \\
\hline Occiput posterior & $\begin{array}{l}\text { Suspect anthropoid or android charac- } \\
\text { teristics; there may be insufficient room } \\
\text { for internal rotation. }\end{array}$ \\
\hline Marked molding & Suspect CPD or fetal malposition. \\
\hline Anterior asynclitism & Suspect CPD. \\
\hline Posterior asynclitism & Suspect CPD in a flat contracted pelvis. \\
\hline
\end{tabular}

CPD, cephalopelvic disproportion; AP, anteroposterior. Modified from Cohen WR, Friedman EA. Labor and Delivery Care: A Practical Guide. John Wiley \& Sons, Ltd., Oxford, 2011, p. 64.

Similarly, when an arrest of dilatation occurs in a funnel pelvis, insurmountable CPD is much more likely than when the arrest has occurred in a large pelvis with parallel or divergent sidewalls. Serial assessment of the cephalopelvic relationships during labor is critical, particularly during descent, because changes in fetal head position and attitude, molding and overlapping of the cranial plates, and separation of pelvic joints can all alter the expectation for a safe normal delivery $[1,27,30]$. Some practitioners find the Müller-Hillis maneuver helpful, especially in the second stage, although there is some controversy about this [31, 32]. It involves gentle but firm pressure on the uterine fundus at the peak of a contraction, revealing to the examiner's intravaginal hand what may be expected in further descent and rotation if the labor continues.

The concept of CPD has often been oversimplified to mean the relative size of the fetal head and the capacity of the maternal pelvis are incompatible with safe vaginal delivery. However, the diagnosis of CPD is under most circumstances more subjective than absolute. When during labor the likelihood of a safe unassisted vaginal birth becomes very low, the diagnosis of CPD may be invoked, absent other factors such as fetal infection or oxygen deprivation. The determination that CPD exists depends on many factors apart from estimates of pelvic and fetal size. It involves assessment of fetal position, attitude, cranial molding, the architectural features of the pelvis (not just its size), as well as the interpretation of the graphed progress of labor. In this context, the pattern of the labor curves should be considered the resultant of the many forces governing how (and whether) cervical dilatation and fetal descent advance. In that sense the curves serve as early indicators of emerging inability of the maternal pelvis to accommodate the fetus safely.

\section{Uterine contractility}

The forces created by a coordinated series of uterine contractions generate cervical dilatation and fetal descent during labor. We know a great deal about the biochemistry and electrophysiology of myometrial contractility [33-35]; but the question of how to determine when contractility is sufficient to cause normal dilatation and descent remains unanswered. Whether this is even determinable is uncertain because a broad range of contractile patterns is found in normal labors [36]. Moreover, there is a complex and unquantifiable balance between contractile (expulsive) force and the mechanical resistance offered by the tissues of the birth canal. This undoubtedly influences the rates of cervical dilatation and of fetal descent. Until we understand more about these intricate and multifaceted relationships and can express them in quantitative terms it will be difficult to add more objectivity to our predictions about the outcome of labor based on clinical measures of uterine contractions.

Four methods are available to assess uterine contractions: manual palpation, tocodynamometry, electrohysterography (EHG), and intrauterine pressure (IUP) monitoring. Each has advantages and limitations [37]. IUP 
determination is considered the most accurate technique, but because it requires rupture of the fetal membranes and an indwelling intraamniotic catheter it accrues a small risk of maternal or fetal infection. Unlike other methods, IUP measurement allows calculation of contractile intensity, but no advantage of IUP assessment over noninvasive techniques has been demonstrated [38, 39]. Moreover, contraction frequency and amplitude account for only a small portion of the variation in rates of cervical dilatation $[40,41]$. The most widely used electronic technique is tocodynamometry, which adequately identifies the frequency and duration, but not the amplitude, of uterine contractions from a strain gauge strapped to the mother's abdomen. EHG is relatively new in clinical use, and holds great promise. It is at least as accurate and reliable as tocodynamometry in identifying contractions [42] and, because it is a direct representation of electromechanical activity in the myometrium, may provide insights into prediction, identification and treatment of dysfunctional labor [43-45].

Contractions in the active phase and second stage should generally be no more frequent than five in ten minutes, and the duration of individual contractions should not exceed $90 \mathrm{~s}$. At least $1 \mathrm{~min}$ of uterine relaxation between contractions is necessary to allow restoration of uterine and brain reoxygenation. Excessive contractility may occur spontaneously or during placental abruption or maternal cocaine intoxication, but uterine hypercontractility is most commonly an iatrogenic response to oxytocin administration. Excessive uterine activity may contribute to catastrophic events, including uterine rupture and, by impeding uterine blood flow, severe fetal asphyxia. In addition, there is mounting evidence of the potential for ischemic brain injury in fetuses exposed to marked head compression from excessive levels of contractility [46-48].

\section{Oxytocin}

Oxytocin is a nonapeptide synthesized primarily in the posterior pituitary gland. Its uterotonic properties and role in milk ejection are well known. It also has several behavioral functions, all related to successful reproduction [49]. It acts principally as a circulating hormone and as a central neurotransmitter. The role of endogenous pituitary oxytocin in parturition is uncertain. The anticipated finding of a rise in maternal plasma oxytocin levels at the onset of labor has not been consistently demonstrated. There is, however, evidence for the presence of oxytocin gene expression in the uterus [50,51], indicating it is synthesized locally and may function as a paracrine rather than an endocrine hormone during parturition. Also, the uterine effects of oxytocin depend more heavily on its receptor concentration than its circulating level, which helps explain why such a large range of pharmacologic doses is necessary among individuals to achieve equivalent effects.

Exogenous oxytocin is widely used. In the US more than $20 \%$ of labors are induced with it, and in some institutions augmentation of spontaneous labor is done in more than half of cases. Shifts in the characteristics of the pregnant population over recent decades have reasonably increased the need for oxytocin use. Larger birth weights, older maternal age, and more prevalent obesity all predispose to dysfunctional labor and the consequent need for augmentation with oxytocin. Advanced maternal age and obesity are also associated with medical complications, including gestational diabetes and hypertensive disorders, which often require induction of labor in the interest of maternal and fetal well-being. These factors, however, do not fully explain today's widespread use of oxytocin. It is principally the consequence of more permissive criteria for the diagnosis and treatment of dystocia, criteria not always supported by available evidence.

Properly employed, pharmacologic oxytocin has a high therapeutic index, but is easily misused [52-55]. Allegations of improper oxytocin use populate a substantial proportion of obstetric medical negligence claims in the US and Europe [56-58], and it has been designated a high-alert medication (one capable of causing significant patient harm if used incorrectly) by the Institute for Safe Medication Practices since 2007 [54].

Because of its potential for harm, therapeutic oxytocin use should be restricted to situations in which its potential benefits clearly outweigh its risks. Using oxytocin to stimulate a labor that began spontaneously and has faltered requires there to be a documented labor dysfunction or a compelling medical reason (infection, severe preeclampsia, etc.) to shorten the labor (Table 6).

Exogenous oxytocin affects primarily the latent phase of labor, which it may shorten considerably. It has a smaller enhancing effect on the rate of normal active phase dilatation and descent. The rate of dilatation may be increased by oxytocin in an active phase slowed by inhibitory factors such as excess analgesia. Oxytocin is quite effective in the treatment of arrest disorders, providing there is no concurrent CPD $[1,6]$. Although it can shorten all aspects of labor, there is no evidence there is any virtue in accelerating a normally progressing labor 
Table 6: Indications for oxytocin administration during spontaneous labor.

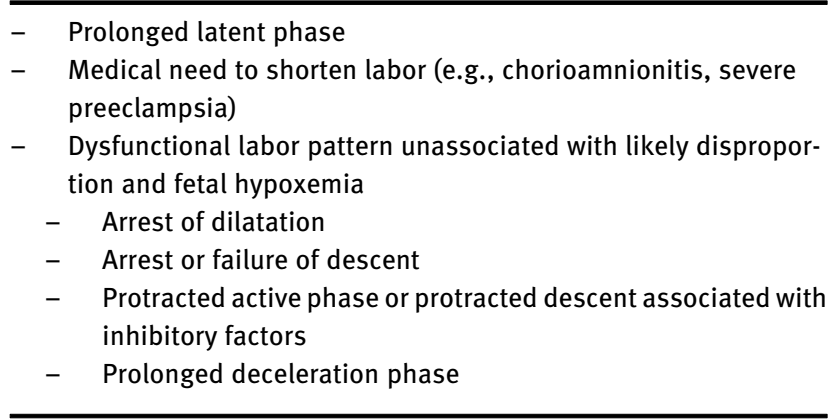

with oxytocin, and there could be harm, particularly if used in the presence of CPD or if hypercontractility develops.

\section{The second stage}

Defined as the time between achievement of full cervical dilatation and delivery of the fetus, the second stage of labor is replete with physiologic and emotional drama. Uterine contractions often strengthen and are supplemented by intense maternal bearing-down (pushing) efforts. These forces propel the fetus through the birth canal, where it rotates to accommodate to the maternal bony and soft tissue features it encounters. Excitement over the impending delivery may be tempered by intensification of pain, especially as the vagina and pelvic floor are distended by the advancing fetal head.

The normality of the second stage has been traditionally judged by its length. Most studies indicate that durations of up to about $3 \mathrm{~h}$ have no demonstrably adverse effect on the condition of the newborn, although rates of maternal birth canal injury, puerperal infection, hemorrhage, and other complications may be encountered earlier [59-65]. The likelihood of a normal vaginal delivery decreases as second stage duration increases. There is some evidence that complications of a very long second stage accrue primarily to those with a demonstrable disorder of descent [66].

The use of epidural anesthesia may lengthen the second stage, but this prolongation should have little effect on the need to resort to cesarean delivery because it is not inherently harmful in the absence of other complicating factors [67]. Active pushing prior to documented full dilatation should always be discouraged. It can result in severe cervical lacerations and may expose the head to excess pressure.
Although widely employed, the use of elapsed time is an insensitive and sometimes misleading approach to assessing second stage labor progress. It ignores the signal physiologic event of the second stage, namely, fetal descent. Judging the second stage by determining the rate of fetal descent, which should be at least $1 \mathrm{~cm}$ (station) per hour in nulliparas and $2 \mathrm{~cm}$ per hour in multiparas, is better. These limits, which were established in women who began forceful bearing-down efforts at full cervical dilatation, need to be reexamined in light of recent changes in pushing styles. Sometimes an open-glottis technique is used, which generates less force than traditional pushing with a long Valsalva maneuver. Also, some now recommend the parturient not commence bearing-down efforts until she feels an overwhelming urge to do so. In some women, this may be long after achieving full cervical dilatation, especially if the head is unengaged or they are receiving epidural analgesia; in others, it may occur simultaneously with the onset of the second stage; and sometimes, when the fetal head is deep in the pelvis, the urge to push begins earlier. The expected rates of descent using these alternatives to traditional pushing styles have not been elucidated precisely [68]. Maternal bearing-down efforts can doubtless speed descent; but it is wrong to assume that descent will cease merely because the patient is not pushing. If there is no descent with or without pushing, some impediment to progress should be suspected.

\section{Pain relief}

Approaches to labor analgesia shift over time, reflecting changing attitudes and expectations of patients and healthcare professionals as well as the availability of safe drugs and anesthetic techniques. The use of psychoprophylactic methods, which have considerable merit as nonpharmacologic approaches to pain management, has diminished recently, as continuous neuraxial (mostly lumbar epidural) analgesic techniques have become more available. In some labor units, more than $90 \%$ of women deliver under epidural analgesia [69]. There is controversy about to what degree such analgesia adversely affects labor. When administered early in labor epidural analgesia sometimes prolongs the latent phase, but does not appear to compromise the likelihood of safe vaginal delivery [70, 71].

A properly administered epidural block (i.e., one that employs appropriate drugs and achieves the correct level of analgesia) has little slowing effect on the normal first stage. It may lengthen the second stage, as the consequence of a partial motor block reducing the effectiveness 
of bearing-down efforts and relaxing pelvic floor muscles, whose normal tone would facilitate the mechanism of labor. In a recent study, continuous infusion of ropivacaine (an anesthetic that exerts minimal neuromuscular blockade) and sufentanil had no effect on second stage duration [72]. A labor progressing abnormally (with, for example, a protracted active phase or an arrest of dilatation) is probably more vulnerable to the inhibitory effects of neuraxial blocks. Most of the inhibitory influences of epidural anesthesia on labor, when they do occur, can be overcome by oxytocin administration.

\section{Fetal risks}

Normal labor and delivery pose little risk to a healthy fetus; but dysfunctional labors, especially if stimulated excessively by oxytocin or terminated by complex operative vaginal delivery, have the potential for considerable harm [6, 73]. Even normal labor may injure a fetus whose reserves are compromised by growth restriction, placental insufficiency, or infection.

As practice patterns have changed, serious direct trauma from obstetric manipulation has become uncommon; most of today's intrapartum brain damage results from ischemic injury. This may occur by two mechanisms, both related to uterine contractility that overwhelms normal compensatory responses: severe reduction in placental oxygen transfer, and excessive head compression that interrupts the intracranial circulation. Many cases are probably multifactorial, and may be exacerbated by infection, other environmental, or genetic factors.

High intramyometrial pressure created by a contraction can collapse the intramural branches of the uterine arteries, reducing blood flow and oxygen delivery to the intervillous space [74]. The resulting fetal oxygen deprivation, if sufficiently severe, can reduce cardiac output and thereby contribute to brain ischemia. The potential ravages of severe fetal hypoxia have long been recognized and extensively studied. Recently, focus has shifted somewhat from concerns about hypoxia to the risks posed to the fetal brain by excessive intrapartum cranial compression [46-48, 75].

Each uterine contraction exposes the fetal head to external pressure. This pressure is enhanced during second stage pushing, and by the compressive force exerted on the head by the pelvic passageway during descent. Intracranial pressures under these conditions are often substantially greater than intraamniotic pressures. Under most circumstances the fetus tolerates these fluctuations in intracranial pressure with equanimity, but the pressures may sometimes be sufficiently high to compromise intracranial blood flow and create brain ischemia $[46,75]$. The contribution of this mechanism to the burden of permanent brain injury is uncertain, but there is evidence from several kinds of studies that when a labor manifests a dysfunctional pattern of dilatation or descent or is stimulated excessively with oxytocin, the risk of brain injury is increased [45-48, 74-79]. While many such affected babies have neonatal encephalopathy (usually without severe acidosis), they may appear well at birth but develop overt neurological problems later.

The only large-scale study with detailed data on labor and delivery events and long-term neuropsychologic followup was the National Collaborative Perinatal Project (NCPP). From this study 18,000 term pregnancies delivered from 1958 to 1974 were analyzed to identify relationships between parturitional events and outcome [73]. A subset of offspring underwent extensive developmental testing over 13 years.

The NCPP pregnancies occurred prior to many modern advances in obstetric and neonatal care. Moreover, the low cesarean rate during the study precluded detailed investigation of the benefits and risks of cesarean delivery in specific situations. Therefore, the conclusions of the NCPP must be applied cautiously to today's practice. Nevertheless, all its outcome results are consistent, thoroughly documented, and exhaustively analyzed. Regrettably, no comparable studies have been done subsequently to confirm or refute the results.

The NCPP showed that objectively defined disorders of dilatation and descent are associated with poor immediate and long-term outcomes for the fetus and surviving child. This potential adversity is largely independent of delivery mode, although difficult operative delivery and other potentially traumatic obstetric manipulations augment hazards. There is a virtue in prompt identification and management, particularly of arrest disorders, the duration of which of which contributes directly to risk. That is not to recommend cesarean delivery as the panacea for any labor that deviates from normal; rather, this approach provides a paradigm for maximizing the frequency of safe atraumatic vaginal delivery and for the early identification of at-risk labors in which the fetus would benefit from prompt delivery.

\section{Summary}

The approach to the evaluation of labor outlined in this review has been thoroughly documented and applied successfully in many institutions $[1,6]$. Each aspect of the evaluation is important, and cannot be interpreted in isolation. A decision about the need for cesarean delivery, for example, requires interpretation of the labor curves 
within the framework of cephalopelvimetric findings and information about maternal and fetal condition. Using the labor curves in this contextual manner provides important prognostic insights. The likelihood the labor will eventuate in a safe normal delivery can be estimated, as can the risk of long-term developmental handicap. This approach has yielded important information as well about the effects on labor of factors including parity, age, obesity, oxytocin, twins, malpositions, and prior cesarean delivery $[1,6]$. It has also provided useful insights into the relationship of complications such as shoulder dystocia to antecedent labor dysfunction [10, 11]. Conscientiously implemented, this approach to labor evaluation will result in a reasonable cesarean rate and minimize risks that may accrue from the labor and delivery process.

Research funding: None declared.

Author contributions: All authors have accepted responsibility for the entire content of this manuscript and approved its submission.

Competing interests: The authors report no conflict of interest.

\section{References}

1. Cohen WR, Friedman EA. Labor and delivery care: a practical guide. Oxford, UK: John Wiley \& Sons, Ltd; 2011.

2. Hofmeyr GJ, Nikodem VC, Wolman WL, Chalmers BE, Kramer T. Companionship to modify the clinical birth environment: effects on progress and perceptions of labour, and breastfeeding. $\mathrm{Br}$ J Obstet Gynaecol 1991;98:756-64.

3. Pascali-Bonaro D, Kroeger M. Continuous female companionship during childbirth: a crucial resource in times of stress or calm. J Midwifery Womens Health 2004;49:19-27.

4. Cohen WR, Friedman EA. The assessment of labor: a brief history. J Perinat Med 2018;46:1-8.

5. Friedman EA. Primigravid labor: a graphicostatistical analysis. Obstet Gynecol 1955;6:567-89.

6. Friedman EA. Labor: clinical evaluation and management, 2nd ed. New York, Appleton-Century-Crofts; 1978.

7. Soni S, Chavan N, Cohen WR. Effect of maternal body mass index on oxytocin treatment for arrest of dilatation. J Perinat Med 2013; 21:1-5.

8. Verdiales M, Pacheco C, Cohen WR. Effect of maternal obesity on the course of labor. J Perinat Med 2009;37:651-5.

9. Chazotte C, Madden R, Cohen WR. Labor patterns in women with previous cesareans. Obstet Gynecol 1990;75:350-5. 2304706.

10. Weizsaecker K, Deaver JR, Cohen WR. Labour characteristics and neonatal Erb's palsy. BJOG 2007;114:1003-9.

11. Deaver JE, Cohen WR. A prediction model for brachial plexus injury. J Perinat Med 2009;37:150-5.

12. Melmed H, Evans MI. Predictive value of cervical dilatation rates. I. Primipara labor. Obstet Gynecol 1976;47:511-5. 1264396.
13. Duncan GR, Costello E. The partogram: a graphic guide to progress in labour. N Z Med J 1975;82:193-5. 1059961.

14. Cibils LA, Hendricks CH. Normal labor in vertex presentation. Am J Obstet Gynecol 1965;91:385-95.

15. Hendricks CH, Brenner WE, Kraus G. Normal cervical dilatation pattern in late pregnancy and labor. Am J Obstet Gynecol 1970; 106:1065-82.

16. Philpott RH, Castle WM. Cervicographs in the management of labour in primigravidae. J Obstet Gynaecol Br Commonw 1972;79: 599-602.

17. Sokol RJ, Stojkov J, Chik L, Rosen MG. Normal and abnormal labor progress: I. A quantitave assessment and survey of the literature. J Reprod Med 1977;18:47-53. 833800.

18. Peisner DB, Rosen MG. Transition from latent to active labor. Obstet Gynecol 1986;68:448-51. 3748488.

19. Zhang J, Toendle J, Mikolajczyk R, Sundaram R, Beaver J, Fraser W. The natural history of the normal first stage of labor. Obstet Gynecol 2010;115;705-10.

20. Zhang J, Landy HJ, Branch DW, Burkman R, Haberman S, Gregory KD, et al. Contemporary patterns of spontaneous labor with normal neonatal outcome. Obstet Gynecol 2010; 116:1281-7.

21. Obstetric Care Consensus Number 1. Safe prevention of the primary cesarean delivery. American college of obstetricians and gynecologists. Obstet Gynecol 2014;123:693-711. 24553167.

22. Cohen WR, Friedman EA. Perils of the new labor management guidelines. Am J Obstet Gynecol. 2015;212:420-7.

23. Cohen WR, Friedman EA. Viewpoint: misguided guidelines for managing labor. Am J Obstet Gynecol 2015;212:753-4.

24. Leveno KJ. Second stage labor: how long is too long?. Am J Obstet Gynecol 2016;214:484-9.

25. Clark SL, Garite TJ, Hamilton EF, Belfort MA, Hankins GD. "Doing something" about the cesarean delivery rate. Am J Obstet Gynecol 2018;219:267-71.

26. Ince JGH, Young MD. The bony pelvis and its influence on labour. J Obstet Gynaecol Br Emp 1940:47:130-90.

27. Maharaj D. Assessing cephalopelvic disproportion: back to the basics. Obstet Gynecol Surv 2010;65:387-95.

28. Stewart DB. The pelvis as a passageway. I. Evolution and adaptations. Br J Obstet Gynaecol 1984;91:611-7.

29. Caldwell WE, Moloy HC. Anatomical variations in the female pelvis and their effects in labor with a suggested classification. Am J Obstet Gynecol 1933;26:479-505.

30. Rustamova S, Predanic M, Cohen WR. Changes in symphysis pubis width during labor. J Perinat Med 2009;37:370-3.

31. March MR, Adair D, Veille JC, Burrus JR. The modified MuellerHillis maneuver in predicting abnormalities of the second stage. Int J Gynaecol Obstet 1996;55:105-9.

32. Thorp JM Jr, Pahel-Short L, Bowes WA Jr. The Mueller-Hillis maneuver: can it be used to predict dystocia? Obstet Gynecol 1993;82:519-22.

33. Wray S. Insights from physiology into myometrial function and dysfunction. Exp Physiol 2015;100:1468-76.

34. Arrowsmith S, Kendrick A, Hanly JA, Noble K, Wray S. Myometrial physiology-time to translate?. Exp Physiol 2014; 99:495-502.

35. Renthal NE, Williams KC, Montalbano AP, Chen C-C, Gao L, Mendelson CR. Molecular regulation of parturition: a myometrial perspective. Cold Spring Harb Perspect Med 2015;5:a023069. 
36. Schulman H, Romney SL. Variability of uterine contractions in normal human parturition. Obstet Gynecol 1970;36:215-21. 5428488.

37. Cohen WR. Clinical assessment of uterine contractions. Int J Gynecol Obstet 2017;139:137-42.

38. Lucidi RS, Chez RA, Creasy RK. The clinical use of intrauterine pressure catheters. J Matern Fetal Med 2001;10:420-2. 11798454

39. Bakker JJ, Verhoeven CJ, van Janssen PF, Lith JM, van Oudgaarden ED, Bloemenkamp KW. Outcomes after internal vs. external tocodynamometry for monitoring labor. N Engl J Med 2010;362; 306-13.

40. Beard RW. Controlling and quantifying uterine activity. Contemp Ob/Gyn 1979;13:75-86.

41. Steer PJ, Carter MC, Beard RW. Normal levels of active contraction area in spontaneous labour. Br J Obstet Gynaecol 1984;91:211-9.

42. Hayes-Gill B, Hassan S, Mirza FG, Ommani S, Himsworth J, Solomon M,et al. Accuracy and reliability of uterine contraction identification using abdominal surface electrodes. Clin Med Insights: Women's Health 2012;5:65-75.

43. Vasak B, Graatsma EM, Hekman-Drost E, Eijkemans MJ, van Leeuwen JH, Visser GH, et al. Uterine electromyography for identification of first stage labor arrest in term nulliparous women with spontaneous onset of labor. Am J Obstet Gynecol 2013;209:232.e1-8.

44. Hiersch L, Salzer L, Aviram A, Hadar E, Yogev Y, Ashwal E. Uterine electrical activity at labor. Is there a correlation between labor stages?. J Maternal Fetal Neonatal Med 2017;30:2620-5.

45. Euliano TY, Marossero D, Nguyen MT, Euliano NR, Principe J, Edwards RK. Spatiotemporal electrohysteography patterns in normal and arrested labor. Am J Obstet Gynecol 2009;200: 54.e1-54.e7.

46. Towner D, Castro MA, Eby-Wilkens E, Gilbert WM. Effect of mode of delivery in nulliparous women on neonatal intracranial injury. N Engl J Med 1999;341:1709-14.

47. Jensen A, Holmer B. White matter damage in 4,725 term-born infants is determined by head circumference at birth-the missing link. Obstet Gynecol Intl 2018;2018:12. Article ID 2120835.

48. Schifrin BS, Deymier P, Cohen WR. Fetal neurological injury related to mechanical forces of labor and delivery. In: Zhang L, Longo L, editors. Stress and developmental programming in health and disease: beyond phenomenology. New York: Nova Biomedical; 2014. pp. 651-88.

49. Raggenbass M, Alberi S, Zaninetti M, Pierson P, Dreifuss JJ. Vasopressin and oxytocin action in the brain: cellular neurophysiological studies. Prog Brain Res 1998;119:263-73.

50. Bossmar T, Osman N, Zilahi E, El Haj MA, Nowotny N, Conlon JM. Expression of the oxytocin gene, but not the vasopressin gene, in the rat uterus during pregnancy: influence of oestradiol and progesterone. J Endocrinol 2007;193:121-6.

51. Lefebvre DL, Giaid A, Bennett $H$, Larivière R, Zingg HH. Oxytocin gene expression in rat uterus. Science 1992;256:1553-5.

52. Clark SL, Simpson KR, Knox GE, Garite TJ. Oxytocin: new perspectives on an old drug. Am J Obstet Gynecol 2009;200: 35.e1-6.

53. Prasad MR, Funai E. Oxytocin use during active labor: too much of a good thing? Am J Obstet Gynecol 2012;207:439-40.

54. Institute for safe medication practices. Available from: www. ismp.org [Accessed June 5 2020].
55. Simpson KR, Knox GE. Oxytocin as a high-alert medication: implications for perinatal patient safety. MCN Am J Matern Child Nurs 2009;34:8-15.

56. Anonymous. Syntocinon medical negligence claims a concern for experts. Medical Irish Law 2015.

57. Jonsson M, Nordén SL, Hanson U. Analysis of malpractice claims with a focus on oxytocin use in labour. Acta Obstet Gynecol Scand 2009;86:315-9. 17364306.

58. Nocon JJ, Coolman DA. Perinatal malpractice. Risks and prevention. J Reprod Med 1987;32:83-90. 3560083.

59. Cohen WR. Influence of the duration of second stage labor on perinatal outcome and puerperal morbidity. Obstet Gynecol 1977;49:266-9. 300151.

60. Laughon SK, Berghella V, Reddy UM, Sundaram R, Lu Z, Hoffman MK. Neonatal and maternal outcomes with prolonged second stage of labor. Obstet Gynecol 2014;124:57-67.

61. Janni W, Schiessl B, Peschers U, Huber S, Strobl B, Klanner E, et al. The prognostic impact of a prolonged second stage of labor on maternal and fetal outcome. Acta Obstet Gynecol Scand 2002; 81:214-21.

62. Hehir MP, Rouse DJ, Miller RS, Ananth CV, Wright JD, Siddiq Z, et al. Second-stage duration and outcomes among women who labored after a prior cesarean delivery. Obstet Gynecol 2018;131:514-22.

63. Rouse DJ, Weiner SJ, Bloom SL, Varner MW, Spong CY, Ramin SM, et al. Second-stage labor duration in nulliparous women: relationship to maternal and perinatal outcomes. Am J Obstet Gynecol 2009;201:357.e1-7.

64. Le Ray C, Audibert F, Goffinet F, Fraser W. When to stop pushing: effects of second-stage expulsion efforts on maternal and neonatal outcomes in nulliparous women with epidural analgesia. Am J Obstet Gynecol 2009;201:361.e1-7.

65. Grantz KL, Sundaram R, Ma L, Hinkle S, Berghella V, Hoffman MK, et al. Reassessing the duration of the second stage of labor in relation to maternal and neonatal morbidity. Obstet Gynecol 2018;131:345-53.

66. Cohen WR, Mahon T, Chazotte C. The very long second stage of labor. In: Proceedings of the third world congress on labor and delivery. New York: Parthenon Publishing; 1998. pp. 348-51.

67. Gimovsky AC, Guarante J, Berghella V. Prolonged second stage in nulliparous[sic] with epidurals: a systematic review. J Matern Fetal Neonatal Med 2017;30:461-5.

68. Lemos A, Amorim MM, Dornelas de Andrade A, de Souza Al, Cabral Filho JE, Correia JB. Pushing/bearing down methods for the second stage of labour. Cochrane Database Syst Rev 2015: CD009124. https://doi.org/10.1002/14651858.CD009124.pub2.

69. Wong CA. Advances in labor analgesia. Intl J Womens Health 2009;1:139-54.

70. Wong CA, Scavone BM, Peaceman AM, McCarthy RJ, Sullivan JT, Diaz NT, et al. The risk of cesarean delivery with neuraxial analgesia given early vs. late in labor. N Engl J Med 2005;352: 655-65.

71. Sng BL, Leong WL, Zeng Y, Siddiqui FJ, Assam PN, Lim Y, et al. Early vs. late initiation of epidural analgesia for labour. Cochrane Database Syst Rev 2014:CD007238. https://doi.org/10.1002/ 14651858.CD007238.pub2.

72. Shen X, Li Y, Xu SQ, Wang N, Fan S, Qin X, et al. Epidural analgesia during the second stage of labor. A randomized controlled trial. Obstet Gynecol 2017;130:1097-103. 
73. Friedman EA, Neff RK. Labor and delivery: impact on offspring. Littleton MA: PSG Publishing; 1987.

74. Rainaldi MA, Perlman JA. Pathophysiology of birth asphyxia. Clin Perinatol 2016;43:409-22.

75. O'Brien WF, Davis SE, Grissom MP, Eng RR, Golden SM. Effect of cephalic pressure on fetal cerebral blood flow. Am J Perinatol 1984;1:223-6.

76. Bakker PC, van Geijn HP. Uterine activity: implications for the condition of the fetus. J Perinat Med 2008;36: $30-7$.
77. Bakker PC, Kurver PH, Kuik DJ, van Geijn HP. Elevated uterine activity increases the risk of fetal acidosis at birth. Am J Obstet Gynecol 2007;196:313.e1-6.

78. Amiel-Tison C, Sureau C, Shnir SM. Cerebral handicap in full-term neonates related to the mechanical forces of labour. Baillieres Clin Obstet Gynecol 1988;2:145-65.

79. Lapeer RJ, Prager RW. Fetal head moulding: finite element analysis of a fetal skull subjected to uterine pressures during the first stage of labour. J Biomech 2001;34:1125-33. 11506783. 